\title{
Correction to: A power efficient, differential multichannel adiabatic electrode stimulator for deep brain stimulation
}

Rohollah Shirafkan $^{1} \cdot$ Omid Shoaei $^{2}$

Published online: 12 May 2018

(C) Springer Science+Business Media, LLC, part of Springer Nature 2018

\section{Correction to:}

Analog Integrated Circuits and Signal Processing https://doi.org/10.1007/s10470-018-1171-z

The original version of the article unfortunately contained an error in figure.

The actual size of Fig. 11 in the published paper did not appear completely. The complete view of Fig. 11 is shown in this erratum.

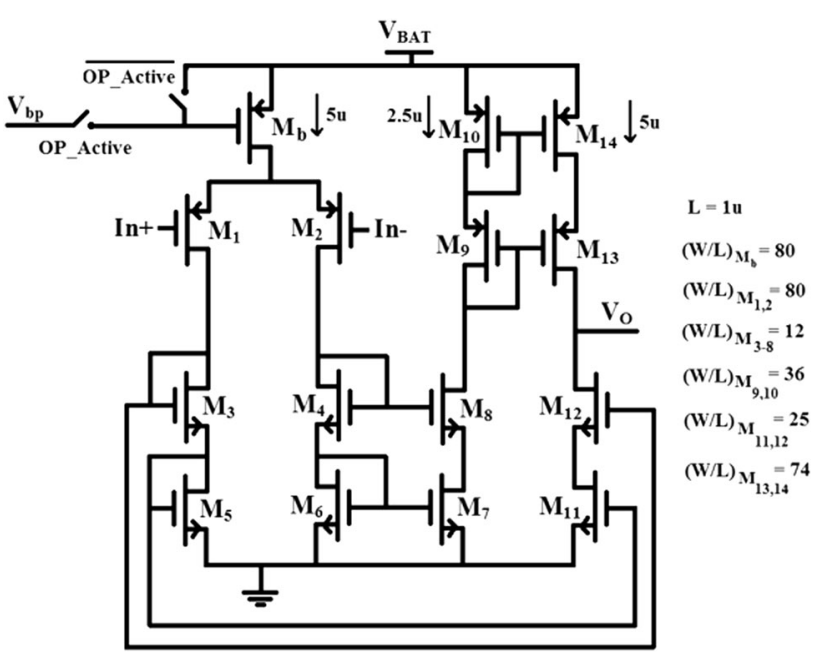

Fig. 11 OTA used in current sensor block

Omid Shoaei

oshoaei@ut.ac.ir

Rohollah Shirafkan

r.shirafkan@ut.ac.ir

1 Bio-Integrated Systems Lab, School of Electrical and Computer Engineering, University of Tehran, Tehran, Iran

2 Nano-Electronic Center of Excellence and Bio-Integrated Systems Lab, School of Electrical and Computer Engineering, College of Engineering, University of Tehran, Tehran, Iran 